\title{
Effect of forward head posture on diaphragmatic excursion in subjects with non-specific chronic neck pain. A case-control study
}

\author{
DOI: https://doi.org/10.5114/pq.2020.95769
}

\author{
Ahmad Mahdi Ahmad', Khaled Mahmoud Kamel'2, Reda Gomaa Mohammed 1 \\ ${ }^{1}$ Department of Physical Therapy for Cardiovascular and Respiratory Disorders, Faculty of Physical Therapy, \\ Cairo University, Giza, Egypt \\ ${ }^{2}$ Department of Chest Diseases, Faculty of Medicine, Cairo University, Giza, Egypt
}

Abstract

Introduction. Forward head posture (FHP) is commonly seen in subjects with chronic neck pain (CNP) and is associated with respiratory function limitations. Therefore, the main aim of this study was to assess the effect of FHP compared with normal head posture (NHP) on diaphragmatic excursion in subjects with non-specific CNP.

Methods. Overall, 30 subjects with CNP aged 35-45 years were recruited for this study and divided into 2 equal groups: the FHP group and the NHP group. The inclusion criteria were non-specific CNP duration of $\geq 3$ months, presence or absence of FHP, FHP confirmed with a craniovertebral angle of $<50^{\circ}$, and male or female sex. The exclusion criteria involved cervical disc problems, cervical spondylosis, traumatic neck pain, chest disease or heart failure, neurological disorders affecting the diaphragm, obesity, and smoking. First, the craniovertebral angle was assessed for subject selection; then, the diaphragmatic excursion and the neck disability index (NDI) were established as the main clinical outcomes of the study. Unpaired t-test was used for statistical analysis.

Results. The diaphragmatic excursion was lower in the FHP group than in the NHP group $(57.00 \pm 15.63$ vs. $67.60 \pm 15.18$; $p=0.070$ ), with no significant difference between the 2 groups. NDI did not differ significantly between the groups.

Conclusions. We suggest that FHP may be related to reduced diaphragmatic excursion in subjects with non-specific CNP. The multimodal approaches to physiotherapy management of non-specific CNP with FHP may consider our suggestion.

Key words: forward head posture, diaphragmatic excursion, non-specific chronic neck pain, neck disability index, craniovertebral angle

\section{Introduction}

Forward head posture (FHP) is a postural misalignment in which the head remains in an anterior position in relation to the vertical line passing between the ears and the shoulders [1]. The condition can be more frequently seen in subjects with chronic neck pain [2]. FHP has a negative impact on the respiratory functions in young adults [3-8]. This could be caused by morphological changes in the thorax in the form of expansion of the upper chest and narrowing of the lower chest, which restricts lower thoracic expansion [8], or a disturbance in the biomechanics of the thoracic cage with limited respiratory movements of the lower ribs [9]. Conversely, FHP can occur as a secondary adaptation to improve compromised lung airways [10], or as a secondary consequence to a morphological change in the thorax (i.e. increased thoracic kyphosis) [11] Apart from FHP, chronic neck pain can also have a positive association with respiratory dysfunction [12-16], presumably owing to several mechanisms such as persistence of pain, reduced cervical range of motion, disturbed neuromuscular control, as well as hyperactivity of sternocleidomastoid and anterior scalene muscles [17]. On this basis, the combined effect of FHP and chronic neck pain could lead to greater respiratory dysfunction.

The diaphragmatic excursion has a positive correlation with respiratory function [18], and up to our knowledge, it has not been assessed before in subjects with non-specific chronic neck pain with or without FHP. Ultrasound imaging is a widely used method for the evaluation of diaphragmatic ex- cursion, as it has many advantages compared with other imaging methods, such as the absence of radiation, non-invasiveness, low price, and real-time imaging [19]. To add, the neck disability index (NDI) is the most commonly applied validated instrument in both clinical and research settings for assessing functional disability in patients with chronic neck pain [20]. Therefore, the aim of this research was to evaluate the effect of FHP on diaphragmatic excursion and NDI compared with normal head posture (NHP) in subjects with non-specific chronic neck pain. The results of this study may offer new insights to the physiotherapy management of nonspecific chronic neck pain.

\section{Subjects and methods}

\section{Subjects}

This was a case-control study in which 30 subjects with chronic neck pain were recruited from Kasr El-Ainy Hospital and the outpatient clinic of the Faculty of Physical Therapy at Cairo University in Egypt. The inclusion criteria were non-specific chronic neck pain (sometimes referred to as mechanical neck pain), defined as neck pain without an identifiable pathological cause and attributed to poor posture, mechanical causes, or occupational activities [21], neck pain with a duration of $\geq 3$ months, presence or absence of FHP, FHP confirmed with a craniovertebral angle of $<50^{\circ}$, male or female sex, age of $35-45$ years, and body mass index (BMI) of

Correspondence address: Ahmad Mahdi, Faculty of Physical Therapy, Cairo University, 1 Gamaa Street, Giza, Egypt, e-mail: ahmed.mahdy@pt.cu.edu.eg 
20-29.9 kg/m². First, the subjects were clinically examined and the medical history was recorded. The exclusion criteria involved cervical disc bulge or prolapse, cervical spondylosis, traumatic neck pain, chest disease or heart failure, neurological disorders affecting the diaphragm, cancer, and rheumatic diseases. We also excluded obese subjects and smokers. The eligible subjects were divided into 2 equal groups: the FHP group (7 males, 8 females) and the NHP group (6 males, 9 females).

\section{Measurements}

\section{Demographic and anthropometric characteristics}

The age, body weight, and height of all patients were reported. BMI was calculated as follows: BMI = body weight $(\mathrm{kg}) /$ height $\left(\mathrm{m}^{2}\right)$ [22].

\section{Craniovertebral angle measurement}

The bio-photogrammetry method was used by the physiotherapist to measure the craniovertebral angle (CVA) and assess FHP [23, 24]. This method of CVA measurement was described in detail by Mani et al. [24]. At first, adhesive markers were placed on the tragus of the right ear and the $\mathrm{C} 7$ spinous process, and the subjects were instructed to stand by side (lateral view) and to look at a target in front of them with both arms beside the body. Then, a digital camera (8 megapixels) was fixed on a tripod at the level of the $7^{\text {th }}$ cervical vertebra and a distance of $1.5 \mathrm{~m}$ from the lateral aspect of the foot on the right side of the subject. Finally, 3 sagittal plane photographs for CVA were taken by the camera to ensure the accuracy of the measurement, and the Surgimap Spine software was used to analyse the digitalized photographs and measure CVA [25]. CVA is the angle between 2 imaginary lines: the horizontal line passing through the spinous process of $\mathrm{C} 7$ and the line passing from $\mathrm{C} 7$ to the tragus of the ear [24]. NHP was reported for CVA $>50^{\circ}$ and FHP was confirmed if CVA was $<50^{\circ}$ [26].

\section{Diaphragmatic ultrasonography}

Ultrasound evaluation of diaphragmatic excursion was performed by a professional respiratory physician who was specialized in diaphragmatic ultrasonography and blind to subject recruitment. To measure diaphragmatic excursion, an ultrasonography device (Hitachi 7000, Japan) was applied with a probe frequency of 2-5 $\mathrm{MHz}$. The anterior subcostal view was used with the patient in the supine position, as diaphragmatic excursion is greater in the supine position than in the sitting position [27]. The right hemi-diaphragmatic excursion was assessed during deep inspiration; this was easier to visualize than the left hemi-diaphragm because of the interference of the stomach and the limited left window of the spleen [28]. The transducer was placed in the anterior aspect of the subcostal regions between the anterior axillary line and the mid-clavicular line, and the subject was instructed to take in deep inspiration and to make full expiration. Two sweeps of the transducer were taken, one in full inspiration and the other in full expiration, and M-mode ultrasound was used to measure diaphragmatic excursion [27].

\section{Neck disability index}

NDI is determined with a 10 -item questionnaire that mea- multiple aspects, such as pain intensity, personal care, lifting activities, reading, the symptom of headache, concentration, sleeping, work, driving, and recreation activities [29]. The Arabic version of the NDI questionnaire was used in this study, which was previously proved valid and reliable [30]; the questionnaires were introduced to the subjects through face-toface interviews with the physiotherapist. As indicated by Vernon and Mior [29], each item has 6 response options, ranging from no disability (0) to total disability (5). The total scoring of the index is therefore 50; however, in the case of 1 or 2 items missing, the total scoring would be 45 or 40 , respectively [29]. The obtained score can be multiplied by 2 to produce a percentage score, with higher scores representing greater disability [29].

\section{Statistical analysis}

Shapiro-Wilk test was first applied to check the normality of data distribution. Then, after confirming the normal distribution of all data, the unpaired $t$-test was used to compare the variables between the 2 groups. Values of $p<0.05$ were considered statistically significant. The GraphPad Prism software served to analyse the data.

\section{Ethical approval}

The research related to human use has complied with all the relevant national regulations and institutional policies, has followed the tenets of the Declaration of Helsinki, and has been approved by the Ethics Committee of Human Scientific Research of the Faculty of Physical Therapy at Cairo University.

\section{Informed consent}

Informed consent has been obtained from all individuals included in this study.

\section{Results}

As shown in Table 1, the mean age equalled $42.47 \pm 8.48$ and $41.00 \pm 10.39$ years in the FHP group and the NHP group, respectively. The mean values of neck pain duration were $2.96 \pm 2.04$ and $2.39 \pm 2.60$ years, respectively. The mean BMI was $25.57 \pm 2.33$ and $24.36 \pm 3.16 \mathrm{~kg} / \mathrm{m}^{2}$, respectively. There was no statistically significant difference between the 2 groups in any of the measured demographic or physical characteristics except for CVA, which was significantly lower in the FHP group. As presented in Table 1 and Figure 1, the diaphragmatic excursion equalled $57.00 \pm$ $15.63 \mathrm{~mm}$ and $67.60 \pm 15.18 \mathrm{~mm}$ in the FHP and NHP groups, respectively, with no significant difference between the 2 groups $(p=0.070)$. NDI was $41.40 \pm 13.95 \%$ and $35.67 \pm$ $11.26 \%$ in the FHP and NHP groups, respectively, with no significant difference between the 2 groups $(p=0.225)$.

\section{Discussion}

This study was conducted to observe the effect of FHP on diaphragmatic excursion and NDI in subjects with nonspecific chronic neck pain compared with those with NHP and non-specific chronic neck pain. To our knowledge, this is the first study to assess diaphragmatic excursion in individuals with non-specific chronic neck pain with or without FHP. The major finding in our study was the observed difference in diaphragmatic excursion between the FHP and NHP groups. The values were lower in the FHP group than in the NHP group $(57.00 \pm 15.63 \mathrm{~mm}$ in FHP vs. $67.60 \pm 15.18 \mathrm{~mm}$ 
Table 1. Demographic, physical, and clinical characteristics of the subjects

\begin{tabular}{|l|c|c|}
\hline Variables & $\begin{array}{c}\text { FHP group } \\
(n=15)\end{array}$ & $\begin{array}{c}\text { NHP group } \\
(n=15)\end{array}$ \\
\hline Age (years) & $42.47 \pm 8.48$ & $41.00 \pm 10.39$ \\
\hline Duration of pain (years) & $2.96 \pm 2.04$ & $2.39 \pm 2.60$ \\
\hline Body weight (kg) & $71.33 \pm 8.95$ & $70.53 \pm 9.52$ \\
\hline Height (cm) & $167.20 \pm 5.80$ & $168.07 \pm 8.00$ \\
\hline BMI (kg/m $\left.{ }^{2}\right)$ & $25.57 \pm 2.33$ & $24.36 \pm 3.16$ \\
\hline CVA $\left(^{\circ}\right)$ & $37.80 \pm 5.95$ & $53.17 \pm 2.60$ \\
\hline Diaphragmatic excursion (mm) & $57.00 \pm 15.63$ & 0.245 \\
\hline Neck disability index (\%) & $41.40 \pm 13.95$ & $67.60 \pm 15.18$ \\
\hline
\end{tabular}

FHP - forward head posture, NHP - normal head posture, BMI - body mass index, CVA - craniovertebral angle

Data are presented as means $\pm S D$ values.

* significant $p$ value $(<0.05)$

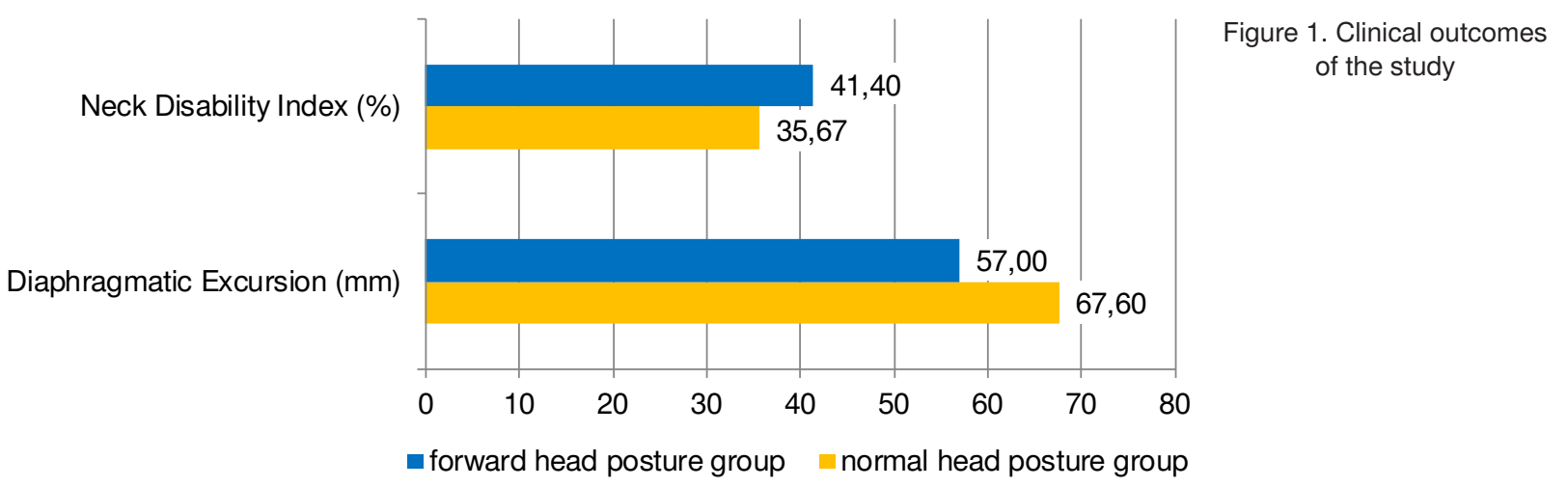

in NHP), but the difference between the 2 groups was not quite statistically significant $(p=0.07)$. It appears that FHP may have a negative impact on diaphragmatic excursion in subjects with non-specific chronic neck pain. This can be obvious as according to Fayssoil et al. [27], the normal value of diaphragmatic excursion measured on the right side should reach $66 \mathrm{~mm}$ during deep inspiration, which was not the case in subjects with FHP in the present study, who presented right diaphragmatic excursion of $57.00 \pm 15.63 \mathrm{~mm}$ during deep inspiration. On the other hand, subjects with NHP showed the right diaphragmatic excursion of $67.60 \pm 15.18 \mathrm{~mm}$ during deep inspiration, which is considered to be a normal value by Fayssoil et al. [27].

The reduced diaphragmatic excursion observed in the FHP group can be explained by the following factors:

(a) Morphological and biomechanical changes involving the lower region of the thoracic cage [8, 9]. FHP causes changes in the shape of the thoracic cage by expanding the upper thorax and constricting the lower thorax, which leads to changes in the biomechanics of breathing and a reduction of movements of the lower ribs [8, 9]. This reduced mobility in the lower thorax caused by FHP can explain the lower diaphragmatic excursion seen in the FHP group.

(b) FHP was also found to cause abdominal muscle shortening, resulting in a reduction of the anteroposterior diameter of the lower thorax [31]. This, in turn, could restrict diaphragmatic excursion.

(c) Moreover, FHP was strongly associated with a reduction in respiratory muscle strength in subjects with chronic neck pain [32]

Notably, several studies have reported that pulmonary functions were lower in subjects with FHP than in those with
NHP [4-8]. Koseki et al. [8] have recently shown that forced vital capacity (FVC), forced expiratory volume in the $1^{\text {st }}$ second $\left(F E V_{1}\right)$, expiratory reserve volume (ERV), inspiratory reserve volume (IRV), and peak expiratory flow (PEF) were significantly lower in FHP subjects than in NHP controls. Similarly, Han et al. [4] have previously reported that FHP was associated with a statistically significant decrease in FVC and $\mathrm{FEV}_{1}$ compared with NHP controls. Besides, Kim et al. [5] have found a significantly positive association between CVA and each of FVC, FEV 1 , PEF, vital capacity (VC), and maximum voluntary ventilation (MVV) in healthy young adults, concluding that the reduced CVA or FHP may act to lower the respiratory functions. Furthermore, Kang et al. [6], observed a positive correlation between CVA and the FVC. Moreover, the sniff nasal inspiratory pressure, a measure of diaphragmatic activity, was significantly lowered in induced FHP compared with the upright sitting position [7].

The second finding in this study was that the NDI was $41.40 \pm 13.95 \%$ in FHP subjects with non-specific chronic neck pain and $35.67 \pm 11.26 \%$ in NHP controls, with a nonsignificant difference between the 2 groups. In accordance with this observation, Ghamkhar and Kahlaee [33] have recently determined no significant association between FHP and pain/disability in patients with chronic neck pain. Also, Tanveer et al. [34] have found no significant influence of FHP on functional disability measured by NDI in undergraduate students. On the contrary, several studies have reported associations between FHP and increased neck pain/disability [26, 35, 36], tension headache [37], and/or reduced functional activities of the upper limbs [38, 39] and shoulder [40]. Yip et al. [26], have observed that the greater the FHP, the greater the neck disability. Also, Kim et al. [35] have sug- 
gested that FHP was a predictive factor for the occurrence of neck pain. Furthermore, $\mathrm{Ha}$ et al. [36] have shown that pain is much bigger in subjects with FHP because of scapular kinematics deformation, which results in transferring the weight of the head to be excessively loaded on posterior cervical structures. Moreover, tension headaches can occur in subjects with FHP owing to the shortening of suboccipital muscles with the activation of muscle trigger points [37]. Besides, other studies have implied that FHP can be linked with reduced activity of upper limb muscles [38] or serratus anterior muscle during lifting activities [39] and even with reduced shoulder elevation because of the increased thoracic spine flexion [40].

It is worth noting that patients with non-specific chronic neck pain have poorer postural control than healthy subjects [41]. A direct relationship between neck pain intensity and increased postural sway has been described in these patients [42]. In addition, the human diaphragm plays a role in maintaining spinal stability or trunk control during upper limb and thoracic cage motion [43, 44]. Furthermore, the diaphragm is organized in such a way that it contributes to both posture and respiration during postural tasks that challenge trunk stability [44].

\section{Limitations}

The limitations of this study include the relatively small sample size, which could affect the generalizability of the results. Also, the differentiation in the clinical outcomes between male and female subjects with non-specific chronic neck pain has not been established. Nevertheless, our study is the first one to assess diaphragmatic excursion in individuals with non-specific chronic neck pain with or without FHP, and our observations can guide future research work.

\section{Conclusions}

We can suggest that FHP may be related to lower diaphragmatic excursion in subjects with non-specific chronic neck pain. The NDI is suggested to be similar in subjects with non-specific chronic neck pain either with or without FHP. These observations need to be confirmed by additional research work with a larger sample size.

\section{Disclosure statement}

No author has any financial interest or received any financial benefit from this research.

\section{Conflict of interest}

The authors state no conflict of interest.

\section{References}

1. Blum CL. The many faces of forward head posture: the importance of differential diagnosis. Cranio. 2019;37(3): 143-146; doi: 10.1080/08869634.2019.1594003.

2. Nejati P, Lotfian S, Moezy A, Moezy A, Nejati M. The relationship of forward head posture and rounded shoulders with neck pain in Iranian office workers. Med J Islam Repub Iran. 2014;28:26.

3. Lee Y, Gong W, Kim B. Correlations between cervical lordosis, vital capacity, T-spine ROM and equilibrium. J Phys Ther Sci. 2011;23(1):103-105; doi: 10.1589/jpts. 23.103.

4. Han J, Park S, Kim Y, Choi Y, Lyu H. Effects of forward head posture on forced vital capacity and respiratory muscles activity. J Phys Ther Sci. 2016;28(1):128-131; doi: 10.1589/jpts.28.128.

5. Kim M-S, Cha Y-J, Choi J-D. Correlation between forward head posture, respiratory functions, and respiratory accessory muscles in young adults. J Back Musculoskelet Rehabil. 2017;30(4):711-715; doi: 10.3233/ BMR-140253.

6. Kang J-I, Jeong D-K, Choi H. Correlation between pulmonary functions and respiratory muscle activity in patients with forward head posture. J Phys Ther Sci. 2018; 30(1):132-135; doi: 10.1589/jpts.30.132.

7. Zafar H, Albarrati A, Alghadir AH, lqbal ZA. Effect of different head-neck postures on the respiratory function in healthy males. Biomed Res Int. 2018;2018:4518269; doi: $10.1155 / 2018 / 4518269$.

8. Koseki T, Kakizaki F, Hayashi S, Nishida N, Itoh M. Effect of forward head posture on thoracic shape and respiratory function. J Phys Ther Sci. 2019;31(1):63-68; doi: 10.1589/jpts.31.63.

9. Szczygieł E, Węglarz K, Piotrowski K, Mazur T, Mętel S, Golec J. Biomechanical influences on head posture and the respiratory movements of the chest. Acta Bioeng Biomech. 2015;17(2):143-148; doi: 10.5277/ABB-001182014-02.

10. Kang J-H, Sung J, Song Y-M, Kim Y-H. Heritability of the airway structure and head posture using twin study. J Oral Rehabil. 2018;45(5):378-385; doi: 10.1111/joor.12620.

11. Quek J, Pua Y-H, Clark RA, Bryant AL. Effects of thoracic kyphosis and forward head posture on cervical range of motion in older adults. Man Ther. 2013;18(1):65-71; doi: 10.1016/j.math.2012.07.005.

12. Dimitriadis Z, Kapreli E, Strimpakos N, Oldham J. Respiratory weakness in patients with chronic neck pain. Man Ther. 2013;18(3):248-253; doi: 10.1016/j.math.2012. 10.014 .

13. Dimitriadis Z, Kapreli E, Strimpakos N, Oldham J. Pulmonary function of patients with chronic neck pain: a spirometry study. Respir Care. 2014;59(4):543-549; doi: 10.4187/respcare.01828.

14. Wirth B, Amstalden M, Perk M, Boutellier U, Humphreys BK. Respiratory dysfunction in patients with chronic neck pain - influence of thoracic spine and chest mobility. Man Ther. 2014;19(5):440-444; doi: 10.1016/j. math.2014.04.011.

15. Dimitriadis Z, Kapreli E, Strimpakos N, Oldham J. Respiratory dysfunction in patients with chronic neck pain: what is the current evidence? J Bodyw Mov Ther. 2016;20(4): 704-714; doi: 10.1016/j.jbmt.2016.02.001.

16. Kahlaee AH, Ghamkhar L, Arab AM. The association between neck pain and pulmonary function: a systematic review. Am J Phys Med Rehabil. 2017;96(3):203-210; doi: 10.1097/PHM.0000000000000608.

17. Kapreli E, Vourazanis E, Strimpakos N. Neck pain causes respiratory dysfunction. Med Hypotheses. 2008;70(5): 1009-1013; doi: 10.1016/j.mehy.2007.07.050.

18. Adel SM, Hieba EG, Hossam SH. Assessment of diaphragmatic mobility by chest ultrasound in relation to $\mathrm{BMI}$ and spirometric parameters. Egypt J Bronchol. 2019;13(2): 232-243; doi: 10.4103/ejb.ejb_73_18.

19. Amin A, Zedan M. Transthoracic ultrasonographic evaluation of diaphragmatic excursion in patients with chronic obstructive pulmonary disease. Egypt J Bronchol. 2018; 12:27-32; doi: 10.4103/1687-8426.217411.

20. Vernon $\mathrm{H}$. The neck disability index: state-of-the-art, 1991-2008. J Manipulative Physiol Ther. 2008;31(7): 491-502; doi: 10.1016/j.jmpt.2008.08.006. 
21. Heintz MM, Hegedus EJ. Multimodal management of mechanical neck pain using a treatment based classification system. J Man Manip Ther. 2008;16(4):217224; doi: 10.1179/106698108790818260.

22. Housh TJ, Cramer JT, Weir JP, Beck TW, Johnson GO. Laboratory manual for exercise physiology, exercise testing, and physical fitness. London, New York: Routledge; 2017.

23. Weber P, Corrêa ECR, Milanesi JM, Soares JC, Trevisan ME. Craniocervical posture: cephalometric and biophotogrammetric analysis. Braz J Oral Sci. 2012;11(3): 416-421; doi: 10.20396/bjos.v11i3.8641399.

24. Mani S, Sharma S, Omar B, Ahmad K, Muniandy Y, Singh DKA. Quantitative measurements of forward head posture in a clinical settings: a technical feasibility study. Eur J Physiother. 2017;19(3):119-123; doi: 10.1080/ 21679169.2017.1296888.

25. Akbar M, Terran J, Ames CP, Lafage V, Schwab F. Use of Surgimap Spine in sagittal plane analysis, osteotomy planning, and correction calculation. Neurosurg Clin N Am. 2013;24(2):163-172; doi: 10.1016/j.nec.2012.12.007.

26. Yip CHT, Chiu TTW, Poon ATK. The relationship between head posture and severity and disability of patients with neck pain. Man Ther. 2008;13(2):148-154; doi: 10.1016/ j.math.2006.11.002.

27. Fayssoil A, Behin A, Ogna A, Mompoint D, Amthor $\mathrm{H}$, Clair B, et al. Diaphragm: pathophysiology and ultrasound imaging in neuromuscular disorders. J Neuromuscul Dis. 2018;5(1):1-10; doi: 10.3233/JND-170276.

28. Cohen E, Mier A, Heywood P, Murphy K, Boultbee J, Guz A. Excursion-volume relation of the right hemidiaphragm measured by ultrasonography and respiratory airflow measurements. Thorax. 1994;49(9):885-889; doi: $10.1136 /$ thx.49.9.885.

29. Vernon $\mathrm{H}$, Mior S. The neck disability index: a study of reliability and validity. J Manipulative Physiol Ther. 1991; 14(7):409-415.

30. Shaheen AAM, Omar MTA, Vernon H. Cross-cultural adaptation, reliability, and validity of the Arabic version of neck disability index in patients with neck pain. Spine. 2013;38(10):E609-E615; doi:10.1097/BRS.0b013e318 28b2d09.

31. Ito $\mathrm{Y}$, Yamada T, Takeda M. Investigation of respiratory function and breathing pattern in elderly people with kyphosis posture [in Japanese]. Rigakuryoho Kagaku. 2007;22(3):353-358; doi: 10.1589/rika.22.353.

32. Kapreli E, Vourazanis E, Billis E, Oldham JA, Strimpakos N. Respiratory dysfunction in chronic neck pain patients. A pilot study. Cephalalgia. 2009;29(7):701-710; doi: 10.1111/j.1468-2982.2008.01787.x.

33. Ghamkhar L, Kahlaee AH. Is forward head posture relevant to cervical muscles performance and neck pain? A case-control study. Braz J Phys Ther. 2019;23(4):346354; doi: 10.1016/j.bjpt.2018.08.007.

34. Tanveer F, Shahid S, Hafeez MM. Effect of forward head posture on neck disability and level of stress among undergraduate students. Isra Med J. 2018;10(2):78-80.

35. Kim D-H, Kim C-J, Son S-M. Neck pain in adults with forward head posture: effects of craniovertebral angle and cervical range of motion. Osong Public Health Res Perspect. 2018;9(6):309-313; doi: 10.24171/j.phrp.2018. 9.6.04.

36. Ha S-M, Kwon O-Y, Yi C-H, Jeon H-S, Lee W-H. Effects of passive correction of scapular position on pain, proprioception, and range of motion in neck-pain patients with bilateral scapular downward-rotation syndrome.
Man Ther. 2011;16(6):585-589; doi: 10.1016/j.math. 2011.05.011.

37. Fernández-de-las-Peñas $C$, Alonso-Blanco C, Cuadrado ML, Gerwin RD, Pareja JA. Trigger points in the suboccipital muscles and forward head posture in tensiontype headache. Headache. 2006;46(3):454-460; doi: 10.1111/j.1526-4610.2006.00288.x.

38. Kwon JW, Son SM, Lee NK. Changes in upper-extremity muscle activities due to head position in subjects with a forward head posture and rounded shoulders. J Phys Ther Sci. 2015;27(6):1739-1742; doi: 10.1589/jpts.27. 1739.

39. Weon J-H, Oh J-S, Cynn H-S, Kim Y-W, Kwon O-Y, Yi $\mathrm{C}-\mathrm{H}$. Influence of forward head posture on scapular upward rotators during isometric shoulder flexion. $J$ Bodyw Mov Ther. 2010;14(4):367-374; doi: 10.1016/j. jbmt.2009.06.006.

40. Singla D, Veqar Z. Association between forward head, rounded shoulders, and increased thoracic kyphosis: a review of the literature. J Chiropr Med. 2017;16(3):220229; doi: 10.1016/j.jcm.2017.03.004.

41. Saadat M, Salehi R, Negahban $H$, Shaterzadeh MJ, Mehravar M, Hessam M. Postural stability in patients with non-specific chronic neck pain: a comparative study with healthy people. Med J Islam Repub Iran. 2018;32:33; doi: 10.14196/mjiri.32.33.

42. Ruhe A, Fejer R, Walker B. On the relationship between pain intensity and postural sway in patients with non-specific neck pain. J Back Musculoskelet Rehabil. 2013;26(4): 401-409; doi: 10.3233/BMR-130399.

43. Hodges PW, Butler JE, McKenzie DK, Gandevia SC. Contraction of the human diaphragm during rapid postural adjustments. J Physiol. 1997;505(Pt 2):539-548; doi: 10.1111/j.1469-7793.1997.539bb.x.

44. Hodges PW, Gandevia SC. Activation of the human diaphragm during a repetitive postural task. J Physiol. 2000;522(Pt1):165-175; doi:10.1111/j.1469-7793.2000. t01-1-00165.xm. 